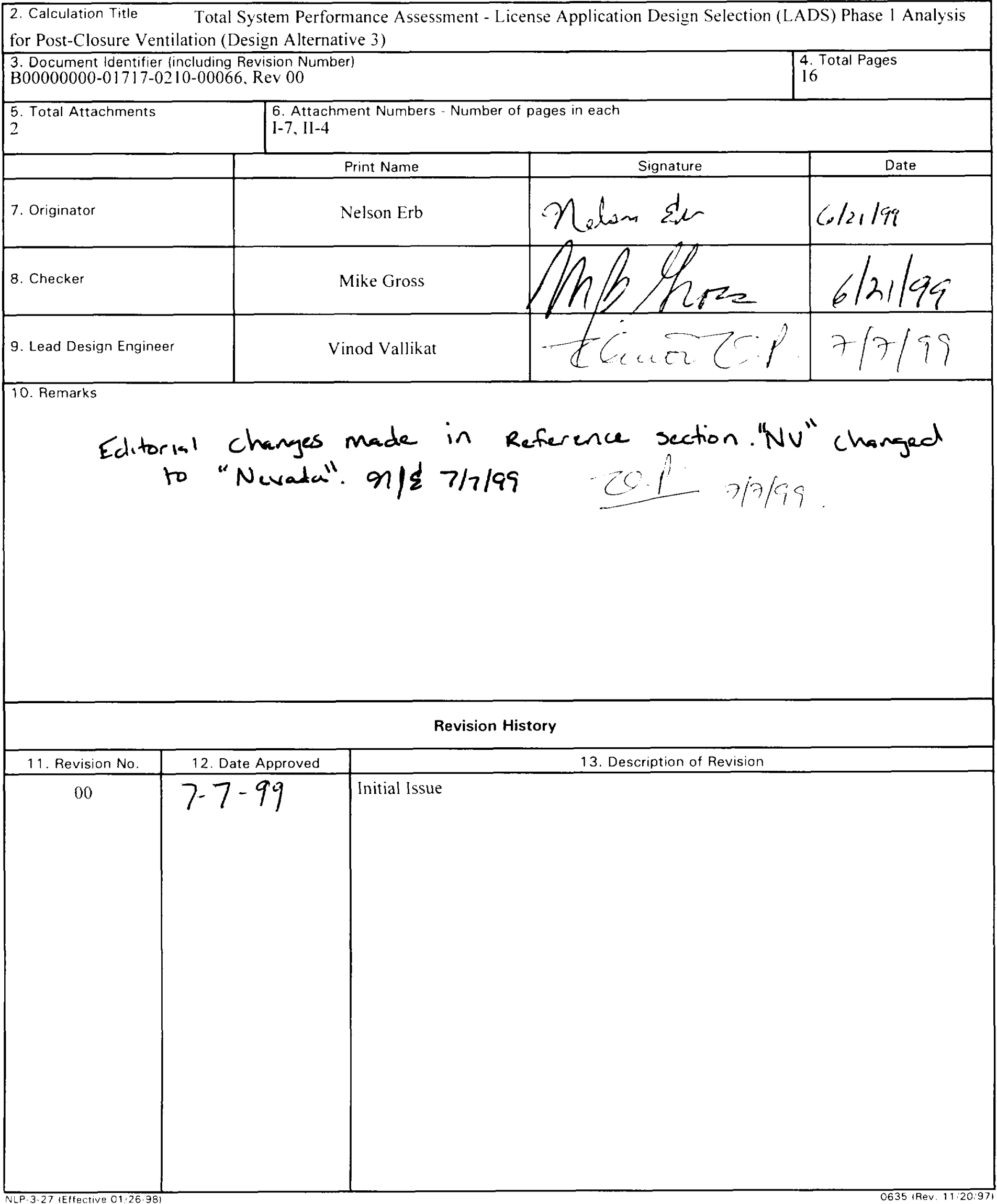




\section{Performance Assessment Operations}

Civilian Radioactive Waste Management System

Management \& Operating Contractor

\section{ENGINEERIMG GALULATION}

Title: $\quad$ Total System Performance Assessment - License Application Design Selection (LADS) Phase 1 Analysis for Post-Closure Ventilation (Design Alternative 3)

Document Identifier:

B00000000-01717-0210-00066 REV 00

Originator:

Nelson Erb

Checker:

Mike Gross

Lead Design Engineer:

Vinod Vallikat

Date:

21 June, 1999 
Title: Total System Performance Assessment - License Application Design Selection (LADS) Phase 1 Analysis for Post-Closure Ventilation (Design Alternative 3)

Document Identifier: B00000000-01717-0210-00066 REV 00

Pago 3 of 16

\section{CONTENTS}

Page

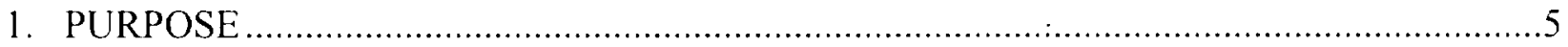

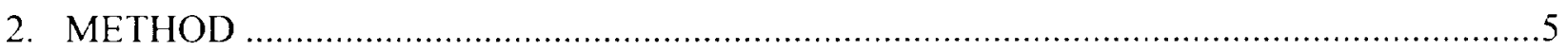

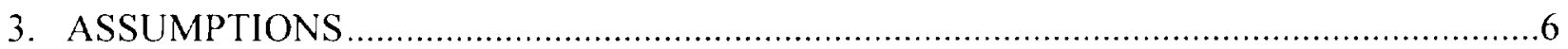

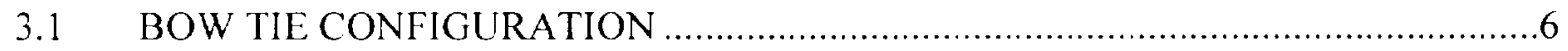

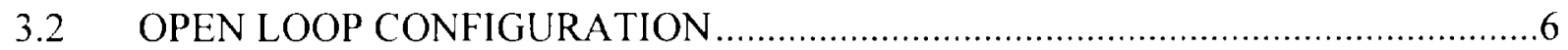

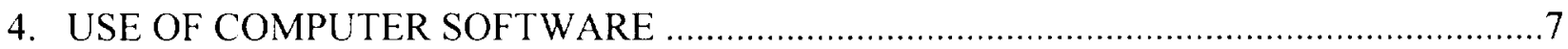

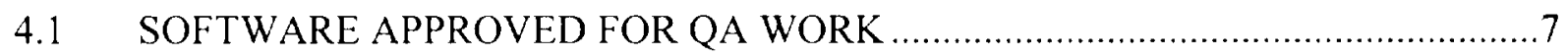

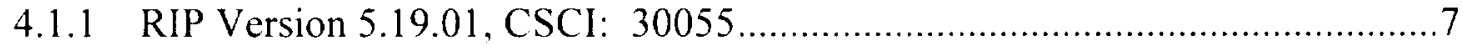

4.1.2 FEHM Version 2.0.0, CSCI: N/A (TBV 564) .................................

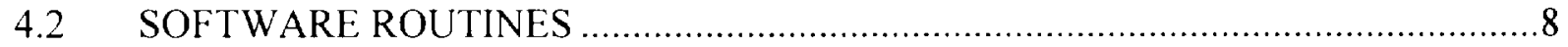

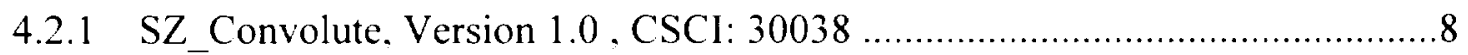

4.2.2 TRANSP Version 1.0, CSCI: 30065 .......................................................

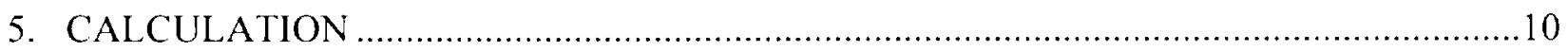

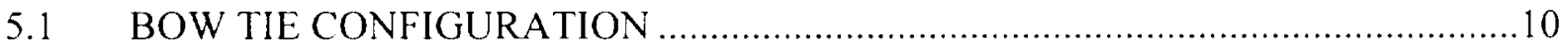

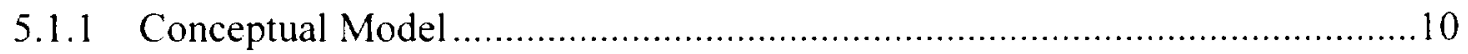

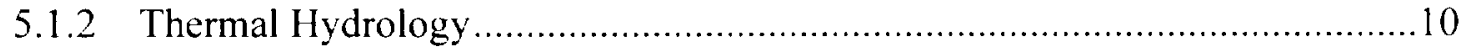

5.1 .3 Waste Package Degradation........................................................ 11

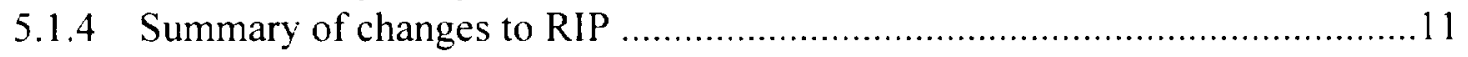

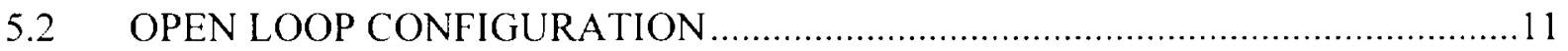

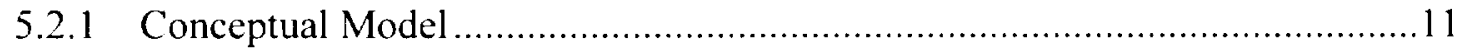

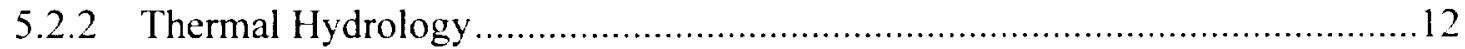

5.2.3 Waste Package Degradation.................................................................. 12

5.2.4 Dripping onto Juvenile Failure Package ............................................... 13

5.2 .5 Summary of Changes to RIP ........................................................ 13

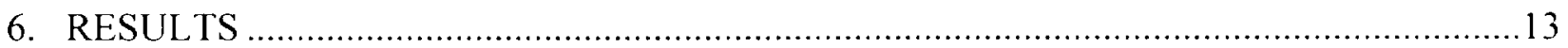


Title: Total System Performance Assessment - License Application Design Selection (LADS) Phase I Analysis for Post-Closure Ventilation (Design Alternative 3)

Document Identifier: B00000000-01717-0210-00066 REV 00

Page 4 of 16

CONTENTS (continued)

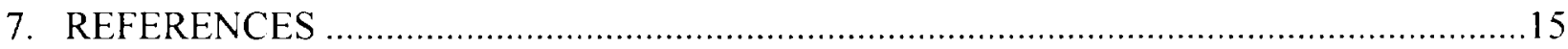

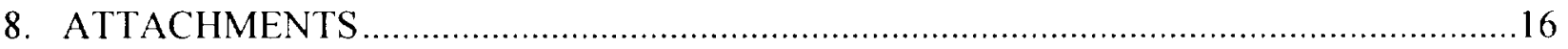




\section{Purpose}

The objective of this report is to evaluate the effect of potential changes to the TSPA-VA base case design on long-term repository performance. The design changes that are evaluated in this report include two configurations for post-closure ventilation. bow tie and open loop (Design Alternative 3 or D3). The following paragraphs briefly describe the motivation for evaluating post-closure ventilation.

The bow tie configuration for post closure ventilation has been identified as a design alternative to the TSPA-VA base case model (CRWMS M\&O, 1998a) that may provide improved performance by reducing the temperature and relative humidity within the waste package drifts. The bow tie configuration for post-closure ventilation is a closed-loop design. In this design. cross drifts are placed in pairs with each drift angling up on opposite sides of the repository (see Figure 1). From the side, the cross drifts and side drifts form the shape of a bow tie. Movement of air through the system is driven by convective heating from the waste packages in the cross drifts.

The open loop configuration is also being considered for its potential to improve post-closure performance of the repository. As with the bow tie configuration, the open loop is designed to decrease temperature and relative humidity within the waste package drifts. For the open loop configuration, air is drawn into the drifts from outside the mountain. The configuration for the repository with open-loop ventilation is similar to the base case repository design with a few added shafts to increase air flow through the drifts.

This report documents the modeling assumptions and calculations conducted to evaluate the long-term performance of Design Alternative 3. The performance measure for this evaluation is dose rate. Results are presented that compare the dose-rate time histories with the new design alternatives to that for the TSPA-VA base case calculation (CRWMS M\&O, 1998a).

\section{Method}

Total system performance assessment calculations require coupling and/or information transfer between models that represent the major components of the repository. These models, their coupling, and input parameter values used in the TSPA-VA base case are described in Total System Performance Assessment - Viability Assessment Base Case (CRWMS M\&O, 1998a). The overall computational system remains unchanged for the post-closure ventilation assessments presented in this report. However, the implementation of various components of the model is changed to account for the effects of the design features. The changes to the base case model are described in the following assumptions and calculation sections of this document. 


\section{Assumptions}

The assumptions for the RIP analyses for Design Alternative 3 are described in this section. Assumptions listed in the base case calculation document (CRWMS M\&O. 1998a) are also applicable.

\subsection{Bow Tie Configuration}

The bow tie configuration for post-closure ventilation was based on the following assumptions:

- The bowtie ventilation has a lifetime of 5.000 years

The actual lifetime of the bow tie configuration for post-closure ventilation is likely greater than 5,000 years. The conservative assumption of a 5,000-year lifetime is adequate for the Phase 1 calculations. Used in section 5.1.

- Only the waste package temperature and waste package degradation change from the TSPAVA base case. All other components of the total system model remain unchanged.

This simplifying assumption is appropriate for Phase 1 of LADS. Other changes to the total system are not known and/or were not evaluated. The changes in temperature and relative humidity are used to reevaluate the waste package degradation model (see next item), but are assumed not to affect the saturation of the invert. Used in section 5.1.

- The assumptions made about waste package degradation are discussed in CRWMS M\&O 1999, Item 1.

Used in Section 5.1.3

- Waste packages temperatures do not change after 100,000 years

Waste package temperatures were only provided for the first 100,000 years after repository closure. The temperature at 100,000 years is observed to be close to the ambient temperature (DTN: MO9904MWDTHM57.000) changes after 100,000 years would be negligible. Therefore the temperature at 100.000 years can be used as a reasonable approximation for the temperature at all times after 100,000 years. Used in Section 5.1.2.

\subsection{Open Loop Configuration}

The open loop configuration for post-closure ventilation was based on the following assumptions:

- The open-loop configuration for ventilation will have a lifetime of 10.000 years The actual lifetime of the open loop configuration for post-closure ventilation is not known. For the purpose of this LADS Phase I calculation, the lifetime is assumed to be 10.000 years. Used in section 5.2 .

- No dripping occurs onto waste packages during the lifetime of the open loop ventilation, 10.000 years. 
It is assumed that the low relative humidity in the ventilated drifts will prevent water from dripping onto waste packages. Used in section 5.2.4.

- The assumptions made about waste package degradation are discussed in CRWMS M\&O 1999. Item 2.

Used in Section 5.2.3

- Waste packages temperatures do not change after 100.000 years

Waste package temperatures were only provided for the first 100,000 years after repository closure. The temperature at 100.000 years is observed to be close to the ambient temperature (DTN: MO9904MWDTHM57.000) and any temperature changes after 100,000 years would be negligible. Therefore the temperature at 100.000 years can be used as a reasonable approximation for the temperature at all times after 100,000 years. Used in Section 5.2.2.

\section{Use of Computer Software}

\subsection{Software Approved for QA Work}

The software used for modeling different components of the repository system in the TSPA-VA total system model are listed in this section. The FEHM software (TBV 564) has not been verified at the time of the calculations and the results from these calculations should be considered TBV (to be verified). The software used for the analyses presented in this document include the same software used for the TSPA-VA base case calculation (CRWMS M\&O, 1998a). No new software was used for the design feature analyses.

WAPDEG and NUFT are used to produce waste package degradation and thermal hydrology inputs to the total system model. These two programs are mentioned several times in the calculation section of this document but are not described in this software section. This is appropriate because WAPDEG and NUFT are only used to create tabular input for the total system model and are not executed during the RIP calculation.

\subsubsection{RIP Version 5.19.01, CSCI: 30055}

Installed on a dual processor Intel Pentium II-based IBM compatible personal computer under the Windows NT 4.0 Operating system.

Since RIP is used as the integrating shell for combining the different components of the repository system, all the input/output files required for running the TSPA-VA base case model are listed in MO9807MWDRIP00.000 and are discussed in CRWMS M\&O. 1998a. Files that were changed or added for individual analyses are listed in Attachment I in directories that correspond to the particular simulation. These files are provided in the DTN:

MO9906MWDRIP66.002. 
Title: Total System Performance Assessment - License Application Design Selection (LADS) Phase I Analysis for Post-Closure Ventilation (Design Alternative 3)

Document Identifier: B00000000-01717-0210-00066 REV 00

Page 8 of 16

a) The RIP computer code (Golder Associates, 1998) is an appropriate tool to perform the following functions that are part of the Total System Performance Assessment: (1) Simulate the release of radionuclides from the engineered barrier system. including the effects of radioactive decay, package failure. dissolution of radionuclides and transport through the engineered barrier system. (2) Simulate the impact of radionuclides on the biosphere. including the determination of exposure to identified populations.

b) This software has been validated over the range it was used. (Software Qualification Report, Repository Integration Program, Version 5.19.01. DI: 30047-2003, Rev. 2. CRWMS M\&O, 1998b)

c) This software was obtained from Software Configuration Management (SCM) in accordance with the appropriate procedures.

\subsubsection{FEHM Version 2.0.0, CSCI: N/A (TBV 564)}

FEHM Version 2.0.0 was compiled as a dynamic link library (DLL) with Digital Visual Fortran 5.0 and is used as an external subroutine (fehmn.dll) to RIP 5.19.01. This DLL was installed on a dual processor Intel Pentium II-based IBM compatible personal computer under the Windows NT 4.0 operating system. Files from the TSPA-VA base case are provided in DTN MO9807MWDRIP00.000 and are described in CRWMS M\&O. 1998a. Any files that were changed are listed in Attachment I and are provided in the DTN: MO9906MWDRIP66.002.

a) The FEHM computer code is an appropriate tool to perform mass transport simulations in the saturated and unsaturated zones below the potential Yucca Mountain repository (Zyvoloski et al., 1997).

b) This software has not been validated over the range it was used.

c) This software was not obtained from SCM in accordance with the appropriate procedures.

\subsection{Software Routines}

\subsubsection{SZ_Convolute, Version 1.0, CSCI: 30038}

SZ_Convolute was compiled as a dynamic link library using Digital Visual Fortran 5.0 and is used as an external subroutine (szconv.dll) to RIP. This DLL was installed on a dual processor Intel Pentium II-based IBM compatible personal computer under the Windows NT 4.0 operating system.

The program is written in the FORTRAN programming language and uses a convolution integral technique to combine concentration breakthrough curves based on unit releases with transient radionuclide mass flux at the water table to determine radionuclide concentrations at a specified 
downstream boundary for which the concentration breakthrough curves were derived. The underlying assumptions in using convolution are: (1) the transport processes and flow fields from the unsaturated zone model and the saturated zone model are independent of one another. (2) the transport processes in the saturated zone model are linear, and (3) steady-state flow is valid for the saturated zone. More information on the formulation and inputs can be found in Software Routine Report for SZ_Convolute (CRWMS M\&O, 1998c).

\subsubsection{TRANSP Version 1.0, CSCI: 30065}

External Functions for the Dissolution Rate and Diffusion Coefficient Calculations within RIP (TRANSP) (CRWMS M\&O, 1998d), contains three DLLs (dynamically linked libraries).

SFDiss, GLDiss, and EDCoef were compiled as dynamic link libraries using Visual $\mathrm{C}++4.0$ to be used as external subroutines (sfdis.dll, gldiss.dll, and edc.dll) to RIP. These DLL's were installed on a dual processor Intel Pentium II-based IBM compatible personal computer under the Windows NT 4.0 operating system.

SFDiss is a subroutine written in C programming language to calculate the commercial spent fuel dissolution rate based on the equation developed from experimental data. More details on the formulas used and inputs for this subroutine can be found in Software Routine Report, External Functions for Dissolution Rate and Diffusion Coefficient Calculations within RIP for TSPA-VA (CRWMS M\&O, 1998d).

GLDiss is a subroutine written in C programming language to calculate the glass dissolution rate based on the equation developed from experimental data. More details on the formulas used and inputs for this subroutine can be found in Software Routine Report. External Functions for Dissolution Rate and Diffusion Coefficient Calculations within RIP for TSPA-VA (CRWMS $\mathrm{M} \& \mathrm{O}, 1998 \mathrm{~d})$.

EDCoef is a subroutine written in $\mathrm{C}$ programming language to calculate the effective diffusion coefficient in an unsaturated porous medium based on the equation developed from experimental data. More details on the formulas used and inputs for this subroutine can be found in Software Routine Report, External Functions for Dissolution Rate and Diffusion Coefficient Calculations within RIP for TSPA-VA (CRWMS M\&O, 1998d). 


\section{Calculation}

The TSPA-VA base case model and parameters were used with only minor changes to the RIP input files to account for the effects of the design features. The base case model and parameters are presented in the Total System Performance Assessment-Viability Assessment Base Case Revision 01 (CRWMS M\&O, 1998a). Components of the base case calculation that were not changed for the design feature analyses are not discussed in this document. Only changes to the model and its parameters are presented here.

The input/output files for these calculations are based on unqualified data. Most parameters used in the TSPA-VA base case calculation are non-qualified (NQ). For the Q-status of individual base case parameters, see CRWMS M\&O 1998a.

\subsection{Bow Tie Configuration}

\subsubsection{Conceptual Model}

The base case model remains unchanged for the bow tie configuration case except for the changes to the temperature and waste package degradation inputs.

\subsubsection{Thermal Hydrology}

The base case model did not include post-closure ventilation. The bow tie configuration for closed loop post-closure ventilation causes a change in the thermal hydrology within the repository drifts. New drift-scale thermal hydrology histories for the bow tie configuration were generated using the finite-difference computer program NUFT (DTN: MO9904MWDTHM57.000). The NUFT calculations generate temperature and relative humidity time histories at the waste package surface for the northeast region of the repository. These histories are then input to WAPDEG v. 3.09 for predictions of long-term waste package degradation.

Average waste package temperature histories for each repository region are also required as a direct input to RIP from NUFT ((DTN: MO9904MWDTHM57.000) for waste form dissolution calculations. The base case temperature files for Commercial Spent Nuclear Fuel (CSNF) and Defense High Level Waste (DHLW) packages calculated using expected value infiltration parameters are replaced with files containing the new thermal histories from NUFT for a repository with the bow tie closed loop ventilation. This information is passed to RIP in input files *.t02 and *.t05 for CSNF and DHLW, respectively. The other temperature input files for RIP are not used for expected value simulations and therefore did not need to be replaced. Two minor changes were made to the input files (*.t02 and *.t05) to conform to the RIP input 
requirements. The first entry for time was changed from 0.0001 to 0 years to provide for a value at time equals zero. The input file also ended at 100,000 years when temperature has returned to near ambient conditions. RIP simulations are carried out to $1,000.000$ years. A new entry was provided for time equals 1,000,000 years with the value equal to the temperature at the 100,000year time(see Section 3.1).

Thermal hydrology data provided for this calculation are NQ.

\subsubsection{Waste Package Degradation}

New waste package degradation histories were generated for the bow tie post-closure ventilation design alternative to account for the changes in temperature and relative humidity associated with the ventilation. WAPDEG v. 3.09 was used to generate the waste package failure histories along with the average number of patches and pits per failed waste package (DTN: MO9906MWDWAP58.000). The temperature and relative humidity data are generated by NUFT (see Section 5.1.2). Waste package degradation is based on the assumptions described in CRWMS M\&O 1999, Item 1.

The base case expected value waste package failure and patch/pit history files for dripping and non-dripping packages (tables *.t20 and *.t35) are replaced with new histories for the bow tie ventilation design alternative with expected value conditions.

Waste package degradation data provided for this calculation are NQ.

\subsubsection{Summary of changes to RIP}

The following is a brief summary of the changes made to the base case RIP input for the bow tie post-closure ventilation simulations:

- $\quad$ replaced tables *.t02 and *.t05 for new expected value thermal histories

- $\quad$ replaced tables *.t20 and *.t35 for new expected value WAPDEG results for dripping and non-dripping packages

\subsection{Open Loop Configuration}

\subsubsection{Conceptual Model}

The base case model remains unchanged for the open loop configuration case except for the changes to the temperature and waste package degradation inputs and the dripping environment 
Title: Total System Performance Assessment - License Application Design Selection (LADS) Phase 1 Analysis for Post-Closure Ventilation (Design Alternative 3)

for the juvenile failure package before 10,000 years.

\subsubsection{Thermal Hydrology}

The base case model did not include post-closure ventilation. The open loop configuration for post-closure ventilation causes a change in the thermal hydrology within the repository drifts. New drift-scale thermal hydrology histories for the open loop configuration were generated using the finite-difference computer program NUFT (DTN MO9904MWDTHM57.000). The NUFT calculations generate temperature and relative humidity time histories at the waste package surface for the northeast region of the repository. These histories are then input to WAPDEG $v$. 3.09 for predictions of long-term waste package degradation.

Average waste package temperature histories for each repository region are also required as a direct input to RIP from NUFT (DTN: MO9904MWDTHM57.000) for waste form dissolution calculations. The base case temperature files for Commercial Spent Nuclear Fuel (CSNF) and Defense High Level Waste (DHLW) packages with expected value infiltration parameters are replaced with files containing the new thermal histories from NUFT for a repository with the open loop ventilation. This information is passed to RIP in input files *.t02 and *.t05 for CSNF and DHLW, respectively. The other temperature input files for RIP are not used for expected value simulations and therefore did not need to be replaced. A minor change was made to the input files (*.t02 and *.t05) to conform to the RIP input requirements. The input files ended at 100,000 years when temperature has returned to near ambient conditions. RIP simulations are carried out to $1,000,000$ years. A new entry was provided for time equals $1,000.000$ years with the value equal to the temperature at the 100.000-year time (see Section 3.2).

Thermal hydrology data provided for this calculation are NQ.

\subsubsection{Waste Package Degradation}

New waste package degradation histories were generated for the open loop post-closure ventilation design alternative to account for the changes in temperature and relative humidity associated with the ventilation. WAPDEG v. 3.09 was used to generate the waste package failure histories along with the average number of patches and pits per failed waste package (DTN: MO9904MWDWAP65.006). The temperature and relative humidity data are generated by NUFT (see Section 5.2.2). Waste package degradation is based on the assumptions described in CRWMS M\&O 1999, Item 2.

The base case expected value waste package failure and patch/pit history files for dripping and non-dripping packages (tables*.t20 and *.t35) are replaced with new histories for the open loop ventilation design alternative with expected value conditions. 
Title: Total System Performance Assessment - License Application Design Selection (LADS) Phase 1 Analysis for Post-Closure Ventilation (Design Alternative 3)

Document Identifier: B00000000-01717-0210-00066 REV 00

Pago 13 of 16

Waste package degradation data provided for this calculation are NQ.

\subsubsection{Dripping onto Juvenile Failure Package}

The relative humidity within the repository drifts remains low for the lifetime of the open loop ventilation (see Section 3.2). With the low relative humidity, it is assumed that no dripping will occur onto the waste packages, therefore there will be no dripping flux through the juvenile failure package for 10,000 years (see Section 3.2). To implement this change in the total system model, a switch (DSWTCH) is added to the RIP parameter list. DSWTCH takes a value of zero for 10,000 years and a value of one after ventilation failure. This switch is multiplied by the dripping flux onto the juvenile failure package (QPASF7). No other waste packages fail during the first 10,000 years so it is not necessary to change the dripping flux onto the other packages.

\subsubsection{Summary of Changes to RIP}

- $\quad$ replaced tables *.t02 and *.t05 for new expected value thermal histories

- $\quad$ replaced tables *.t20 and *.t35 for new expected value WAPDEG results for dripping and non-dripping packages

- $\quad$ add parameter DSWTCH and modify parameter QPASF7 so there is no dripping onto the juvenile failure package during the lifetime of the ventilation

\section{Results}

Since unqualified inputs were used in the development of the results presented in this section, they should be considered TBV. This document will not directly support any construction, fabrication, or procurement activity, and therefore. the inputs and outputs are not required to be procedurally controlled as TBV. However, any use of the data from this analysis for inputs into documents supporting construction, fabrication, or procurement is required to be controlled as TBV in accordance with appropriate procedures.

The following table summarizes several post-closure performance measures. These performance measures are useful for providing objective measures of the performance-related benefit of a LADS feature in comparison to the base case. The suggested post-closure performance measures are as follows:

- The peak dose rate and its time of occurrence during the first 10,000 years after closure. This is a reasonable criterion because 10,000 years is the likely regulatory period. 
Title: Total System Performance Assessment - License Application Design Selection (LADS) Phase 1 Analysis for Post-Closure Ventilation (Design Alternative 3)

Document Identifier: B00000000-01717-0210-00066 REV 00

Pago 14 of 16

- The peak dose rate and its time of occurrence during 1.000 .000 years.

Periods up to $1,000,000$ years may be considered during licensing. Note that the peak dose rate often occurs during the first or second superpluvial (SP) period. around 300,000 or 700.000 years.

- A Figure of Merit (FOM) based on the weighted dose rate over the time period of interest. The FOM is defined as:

$$
F O M=\frac{1}{\ln \left(1 \times 10^{6}\right)-\ln \left(1 \times 10^{3}\right)} \int_{0}^{T} \frac{r}{t} d t,
$$

where

$r$ is the dose rate (mrem/year),

$t$ is the time (years), and

$T$ is the period of interest

(years).

Note that this FOM has the units of mrem/year and that the time variable is inside the integral sign, which has the effect of weighting early-time doses more than late-time doses. Results for the simple FOM calculation are found in "f26 da3 fom.xls" in DTN: MO9906MWDRIP66.002.

\begin{tabular}{|c|c|c|c|c|c|c|}
\hline \multirow[b]{2}{*}{ Feature } & \multirow[b]{2}{*}{ Description } & \multirow[b]{2}{*}{ FOM } & \multicolumn{2}{|c|}{10,000 -Year Duration } & \multicolumn{2}{|c|}{$1,000,000$-Year Duration } \\
\hline & & & $\begin{array}{l}\text { Peak Rate } \\
(\mathrm{mrem} / \mathrm{yr})\end{array}$ & $\begin{array}{l}\text { Time } \\
\text { (years) }\end{array}$ & $\begin{array}{l}\text { Peak Rate } \\
(\mathrm{mrem} / \mathrm{yr})\end{array}$ & $\begin{array}{l}\text { Time } \\
\text { (years) }\end{array}$ \\
\hline Base case & Base Case & 25.02 & 0.0422 & 10000 & 300.9 & 317000 \\
\hline D3 3 & $\begin{array}{l}\text { Bow tie configuration, post- } \\
\text { closure ventilation }\end{array}$ & $27.63^{-}$ & 0.01388 & 5600 & 290.3 & 317000 \\
\hline D3 & $\begin{array}{l}\text { Open loop configuration, post- } \\
\text { closure ventilation }\end{array}$ & 24.92 & 0.007906 & 5600 & 268.9 & 316000 \\
\hline
\end{tabular}

The dose-rate histories for the post-closure ventilation cases are provided in Figures 2 and 3 . For the 10,000-year cases (Figure 2) dose rates are at or below the base case results for the first 5.600 years and are driven by the release of radionuclides from the juvenile failure package. The open loop configuration results are lower than the base case and bow tie results since there is no advective release from the juvenile failure package. After the juvenile failure, the dose rates for both ventilation cases decrease since no other packages fail during the first 10,000 years.

For the 1,000,000-year results there is little difference between the base case and the post-closure ventilation cases (Figure 3). The post-closure ventilation lasts for only 10.000 years for the open loop case and 5,000 years for the bow tie configuration. The short duration of ventilation has little impact on dose over the course of 1.000 .000 years. 
Title: Total System Performance Assessment - License Application Design Selection (LADS) Phase 1 Analysis for Post-Closure Ventilation (Design Alternative 3)

Document Identifier: B00000000-01717-0210-00066 REV 00

Page 15 of 16

\section{References}

CRWMS M\&O 1998a. Total System Performance Assessment-Viability Assessment Base Case. B00000000-01717-0210-00011 REV 01. Las Vegas, Nevada: CRWMS M\&O. ACC: MOL.19981202.0279.

CRWMS M\&O 1998b. Software Qualification Report, Repository Integration Program (RIP), Version 5.19.01. Software Configuration Identifier (CSCI): 30055 V.5.19.01. DI: 30047-2003 REV 02. Las Vegas, Nevada: CRWMS M\&O. ACC: MOL.19980916.0337.

CRWMS M\&O 1998c. Software Routine Report for $S Z$ Convolute. Version 1.0 DI: 30038-2999 REV 00. Las Vegas, Nevada: CRWMS M\&O. ACC: MOL.19981103.0084

CRWMS M\&O 1998d. Software Routine Report, External Functions for Dissolution Rate and Diffusion Coefficient Calculations within RIP for TSPA-VA. Version 1.0 DI: 30065-2999 REV 00. Las Vegas, Nevada: CRWMS M\&O. ACC: MOL.19981120.0103

CRWMS M\&O 1999. Design Input Transmittal for WAPDEG and RIP Output and Analysis for DA3a (Post-Closure Ventilation - Bowtie) and DA3b (Post-Closure Ventilation - Open Loop Hybrid). Input Tracking No. SSR-PA-99045.T. Las Vegas, Nevada: CRWMS M\&O. ACC: MOL.19990217.0217.

Golder Associates 1998. RIP Integrated Probabilistic Simulator for Environmental Systems: Theory Manual and User's Guide. Redmond, Washington: Golder Associates Inc. TIC: 238560.

Zyvoloski, G.A.; Robinson, B.A.; Dash, Z.V.; and Trease, L.L. 1997. Summary of the Models and Methods for the FEHM Application - A Finite-Element Heat-and Mass-Transfer Code. LA-13307-MS. Los Alamos, New Mexico: Los Alamos National Laboratory. TIC: 235587. 
Title: Total System Performance Assessment - License Application Design Selection (LADS) Phase 1 Analysis for Post-Closure Ventilation (Design Alternative 3)

Document Identifier: B00000000-01717-0210-00066 REV 00

Page 16 of 16

\section{Attachments}

I. Directories of Input/Output Files (7 page)

II. Result Figures (4 pages) 
Title: Total System Performance Assessment - License Application Design Selection (LADS) Phase 1 Analysis for Post-Closure Ventilation (Design Alternative 3)

Document Identifier: B00000000-01717-0210-00066 REV 00

Page I-1 of $1-7$

\section{Attachment I}

\section{Directories of Input/Output Files}

For details and explanation of directories and files, see readme.txt file in DTN: MO9906MWDRIP66.002 
Title: Total System Performance Assessment - License Application Design Selection (LADS) Phase l Analysis for Post-Closure Ventilation (Design Alternative 3)

Document Identifier: B00000000-01717-0210-00066 REV 00

\begin{tabular}{cccc}
$02 / 23 / 99$ & $07: 51 \mathrm{a}$ & $<$ DIR $>$ &. \\
$02 / 23 / 99$ & $07: 51 \mathrm{a}$ & $<$ DIR $>$ &.. \\
$02 / 23 / 99$ & $07: 52 \mathrm{a}$ & $<$ DIR $>$ & D3ae4 \\
$02 / 23 / 99$ & $07: 52 \mathrm{a}$ & $<$ DIR $>$ & D3ae6 \\
$02 / 23 / 99$ & $07: 52 \mathrm{a}$ & $<$ DIR $>$ & d3be4 \\
$02 / 23 / 99$ & $07: 52 \mathrm{a}$ & $<$ DIR $>$ & $\mathrm{d} 3 \mathrm{be} 6$ \\
$01 / 12 / 99$ & $06: 56 \mathrm{p}$ & $851.456 \mathrm{f} 26$ da3_fom.xls \\
$04 / 06 / 99$ & $09: 34 \mathrm{p}$ & \multicolumn{2}{c}{12,999 readme.txt } \\
& 7 File(s) & \multicolumn{2}{c}{951 bytes }
\end{tabular}

Directory of G: $\backslash \mathrm{D} 3 \mathrm{ae} 4$

$\begin{array}{llc}02 / 23 / 99 & 07: 52 \mathrm{a} & <\text { DIR }> \\ 02 / 23 / 99 & 07: 52 \mathrm{a} & < \\ 12 / 10 / 98 & 03: 25 \mathrm{p} & 787 \text { baserun } 1 . \text { dat } \\ 12 / 10 / 98 & 02: 15 \mathrm{p} & 498,181 \text { DA3AE4.BAK } \\ 12 / 10 / 98 & 03: 32 \mathrm{p} & 88,192 \text { da3ae4.BPF } \\ 12 / 10 / 98 & 03: 32 \mathrm{p} & 11.993 \text { da3ae4.bsr } \\ 12 / 10 / 98 & 03: 27 \mathrm{p} & 578.785 \text { da3ae4.BTF } \\ 12 / 10 / 98 & 03: 32 \mathrm{p} & 2,658.692 \text { da3ae4.btr } \\ 12 / 10 / 98 & 03: 32 \mathrm{p} & 2.447 \text { da3ae4.out } \\ 12 / 10 / 98 & 03: 27 \mathrm{p} & 498,181 \text { DA3AE4.RP } \\ 04 / 04 / 98 & 11: 43 \mathrm{p} & 11,979 \text { da3ae4.t01 } \\ 12 / 10 / 98 & 02: 14 \mathrm{p} & 6,587 \text { da3ae4.t02 } \\ 04 / 04 / 98 & 11: 44 \mathrm{p} & 11.964 \text { da3ae4.t03 } \\ 04 / 04 / 98 & 11: 44 \mathrm{p} & 12.266 \text { da3ae4.t04 } \\ 12 / 10 / 98 & 02: 14 \mathrm{p} & 6,587 \text { da3ae4.t05 } \\ 04 / 04 / 98 & 11: 44 \mathrm{p} & 11.715 \text { da3ae4.t06 } \\ 03 / 28 / 98 & 07: 25 \mathrm{a} & 6,070 \text { da3ae4.t07 } \\ 03 / 27 / 98 & 09: 33 \mathrm{a} & 6,002 \text { da3ae4.t08 } \\ 03 / 28 / 98 & 07: 30 \mathrm{a} & 6.002 \text { da3ae4.t09 } \\ 03 / 27 / 98 & 09: 33 \mathrm{a} & 6,002 \text { da3ae4.t10 } \\ 03 / 27 / 98 & 09: 34 \mathrm{a} & 6,070 \text { da3ae4.t11 } \\ 03 / 27 / 98 & 09: 34 \mathrm{a} & 6,070 \text { da3ae4.t12 } \\ 03 / 27 / 98 & 09: 35 \mathrm{a} & 6,070 \text { da3ae4.t13 } \\ 03 / 27 / 98 & 09: 35 \mathrm{a} & 6,070 \text { da3ae4.t14 } \\ 03 / 27 / 98 & 09: 35 \mathrm{a} & 6,070 \text { da3ae4.t15 } \\ 03 / 27 / 98 & 08: 27 \mathrm{a} & 6,070 \text { da3ae4.t16 } \\ 03 / 27 / 98 & 08: 27 \mathrm{a} & 6,002 \text { da3ae4.t17 } \\ 03 / 27 / 98 & 08: 28 \mathrm{a} & 6,002 \text { da3ae4.t18 } \\ 03 / 27 / 98 & 08: 34 \mathrm{a} & 6,002 \text { da3ae4.t19 } \\ 12 / 03 / 98 & 09: 46 \mathrm{a} & 6.311 \text { da3ae4.t20 } \\ 03 / 27 / 98 & 08: 35 \mathrm{a} & 6,002 \text { da3ae4.t2 } \\ & & \end{array}$


Title: Total System Performance Assessment - License Application Design Selection (LADS) Phase 1 Analysis for Post-Closure Ventilation (Design Alternative 3)

Document Identifier: B00000000-01717-0210-00066 REV 00

Page 1-3 of 1-7

$\begin{array}{llc}03 / 27 / 98 & 08: 36 \mathrm{a} & 6,070 \text { da3ae4.t22 } \\ 03 / 27 / 98 & 08: 41 \mathrm{a} & 6.070 \text { da3ae4.t23 } \\ 03 / 27 / 98 & 08: 41 \mathrm{a} & 6.070 \text { da3ae4.t24 } \\ 03 / 27 / 98 & 09: 41 \mathrm{a} & 6,002 \text { da3ae4.t25 } \\ 03 / 27 / 98 & 09: 41 \mathrm{a} & 6,070 \text { da3ae4.t26 } \\ 03 / 27 / 98 & 09: 41 \mathrm{a} & 698 \text { da3ae4.t27 } \\ 03 / 27 / 98 & 09: 41 \mathrm{a} & 6,002 \text { da3ae4.t28 } \\ 03 / 27 / 98 & 09: 42 \mathrm{a} & 6,002 \text { da3ae4.t29 } \\ 03 / 27 / 98 & 09: 42 \mathrm{a} & 6,070 \text { da3ae4.t30 } \\ 03 / 27 / 98 & 09: 42 \mathrm{a} & 6,070 \text { da3ae4.t31 } \\ 03 / 27 / 98 & 09: 43 \mathrm{a} & 6,070 \text { da3ae4.t32 } \\ 03 / 27 / 98 & 09: 43 \mathrm{a} & 6,070 \text { da3ae4.t33 } \\ 03 / 30 / 98 & 02: 38 \mathrm{p} & 2,874 \text { da3ae4.t34 } \\ 11 / 04 / 98 & 02: 11 \mathrm{p} & 3,319 \text { da3ae4.t35 } \\ 03 / 30 / 98 & 02: 30 \mathrm{p} & 1,990 \text { da3ae4.t36 } \\ 04 / 01 / 98 & 06: 57 \mathrm{a} & 1,865 \text { da3ae4.t37 } \\ 12 / 11 / 98 & 08: 50 \mathrm{a} & 3,080 \text { DOSE.DAT } \\ 10 / 27 / 92 & 05: 00 \mathrm{a} & 5,527 \text { EGAVGA.BGI } \\ 12 / 10 / 98 & 03: 25 \mathrm{p} & 160,935 \text { ptrk.expval } \\ 12 / 10 / 98 & 03: 25 \mathrm{p} & 185 \text { sz_convolute2.dat } \\ 51 \text { File(s) } & 4,736,210 \text { bytes }\end{array}$

Directory of G: $\backslash D 3 a e 6$

$\begin{array}{llcc}02 / 23 / 99 & 07: 52 \mathrm{a} & <\mathrm{DIR}> \\ 02 / 23 / 99 & 07: 52 \mathrm{a} & <\mathrm{DIR}> & . . \\ 04 / 04 / 98 & 11: 19 \mathrm{p} & 788 \text { baserunl.dat } \\ 12 / 10 / 98 & 09: 51 \mathrm{a} & 498.181 \text { DA3AE6.BAK } \\ 12 / 10 / 98 & 04: 22 \mathrm{p} & 88,192 \text { da3ae6.BPF } \\ 12 / 10 / 98 & 04: 22 \mathrm{p} & 11.993 \text { DA3AE6.bsr } \\ 12 / 10 / 98 & 02: 15 \mathrm{p} & 580,585 \text { da3ae6.BTF } \\ 12 / 10 / 98 & 04: 22 \mathrm{p} & 25,695.092 \text { DA3AE6.btr } \\ 12 / 10 / 98 & 04: 22 \mathrm{p} & 2.522 \text { da3ae6.out } \\ 12 / 10 / 98 & 02: 15 \mathrm{p} & 498,181 \text { DA3AE6.RP } \\ 04 / 04 / 98 & 11: 43 \mathrm{p} & 11.979 \text { da3ae6.t01 } \\ 12 / 10 / 98 & 02: 14 \mathrm{p} & 6.587 \text { da3ae6.t02 } \\ 04 / 04 / 98 & 11: 44 \mathrm{p} & 11.964 \text { da3ae6.t03 } \\ 04 / 04 / 98 & 11: 44 \mathrm{p} & 12.266 \text { da3ae6.t04 } \\ 12 / 10 / 98 & 02: 14 \mathrm{p} & 6.587 \text { da3ae6.t05 } \\ 04 / 04 / 98 & 11: 44 \mathrm{p} & 11.715 \text { da3ae6.t06 } \\ 03 / 28 / 98 & 07: 25 \mathrm{a} & 6.070 \text { da3ae6.t07 } \\ 03 / 27 / 98 & 09: 33 \mathrm{a} & 6.002 \text { da3ae6.t08 } \\ 03 / 28 / 98 & 07: 30 \mathrm{a} & 6.002 \text { da3ae6.t09 }\end{array}$


Title: Total System Performance Assessment - License Application Design Selection (LADS) Phase 1 Analysis for Post-Closure Ventilation (Design Alternative 3)

Document Identifier: B0000000-01717-0210-00066 REV 00

Page 1-4 of 1-7

$\begin{array}{llc}03 / 27 / 98 & 09: 33 \mathrm{a} & 6,002 \text { da3ae6.t10 } \\ 03 / 27 / 98 & 09: 34 \mathrm{a} & 6,070 \text { da3ae6.t1 } 1 \\ 03 / 27 / 98 & 09: 34 \mathrm{a} & 6,070 \text { da3ae6.t12 } \\ 03 / 27 / 98 & 09: 35 \mathrm{a} & 6,070 \text { da3ae6.t13 } \\ 03 / 27 / 98 & 09: 35 \mathrm{a} & 6.070 \text { da3ae6.t14 } \\ 03 / 27 / 98 & 09: 35 \mathrm{a} & 6.070 \text { da3ae6.t15 } \\ 03 / 27 / 98 & 08: 27 \mathrm{a} & 6.070 \text { da3ae6.t16 } \\ 03 / 27 / 98 & 08: 27 \mathrm{a} & 6,002 \text { da3ae6.t17 } \\ 03 / 27 / 98 & 08: 28 \mathrm{a} & 6,002 \text { da3ae6.t18 } \\ 03 / 27 / 98 & 08: 34 \mathrm{a} & 6,002 \text { da3ae6.t19 } \\ 12 / 03 / 98 & 09: 46 \mathrm{a} & 6,311 \text { da3ae6.t20 } \\ 03 / 27 / 98 & 08: 35 \mathrm{a} & 6,002 \text { da3ae6.t21 } \\ 03 / 27 / 98 & 08: 36 \mathrm{a} & 6.070 \text { da3ae6.t22 } \\ 03 / 27 / 98 & 08: 41 \mathrm{a} & 6,070 \text { da3ae6.t23 } \\ 03 / 27 / 98 & 08: 41 \mathrm{a} & 6,070 \text { da3ae6.t24 } \\ 03 / 27 / 98 & 09: 41 \mathrm{a} & 6.002 \text { da3ae6.t25 } \\ 03 / 27 / 98 & 09: 41 \mathrm{a} & 6,070 \text { da3ae6.t26 } \\ 03 / 27 / 98 & 09: 41 \mathrm{a} & 698 \text { da3ae6.t27 } \\ 03 / 27 / 98 & 09: 41 \mathrm{a} & 6,002 \text { da3ae6.t28 } \\ 03 / 27 / 98 & 09: 42 \mathrm{a} & 6,002 \text { da3ae6.t29 } \\ 03 / 27 / 98 & 09: 42 \mathrm{a} & 6.070 \text { da3ae6.t30 } \\ 03 / 27 / 98 & 09: 42 \mathrm{a} & 6,070 \text { da3ae6.t31 } \\ 03 / 27 / 98 & 09: 43 \mathrm{a} & 6,070 \text { da3ae6.t32 } \\ 03 / 27 / 98 & 09: 43 \mathrm{a} & 6,070 \text { da3ae6.t33 } \\ 03 / 30 / 98 & 02: 38 \mathrm{p} & 2,874 \text { da3ae6.t34 } \\ 11 / 04 / 98 & 02: 11 \mathrm{p} & 3,319 \text { da3ae6.t35 } \\ 03 / 30 / 98 & 02: 30 \mathrm{p} & 1,990 \text { da3ae6.t36 } \\ 04 / 01 / 98 & 06: 57 \mathrm{a} & 1,865 \text { da3ae6.t37 } \\ 12 / 11 / 98 & 08: 49 \mathrm{a} & 28,280 \text { DOSE.DAT } \\ 10 / 27 / 92 & 05: 00 \mathrm{a} & 5,527 \text { EGAVGA.BGI } \\ 12 / 09 / 98 & 03: 45 \mathrm{p} & 160,936 \text { ptrk.expval } \\ 04 / 04 / 98 & 11: 44 \mathrm{p} & 186 \text { sz_convolute2.dat } \\ 51 & \text { File(s) } & 27,799,688 \text { bytes } \\ 03 & \end{array}$

Directory of G:id3be4

\begin{tabular}{llcc}
$02 / 23 / 99$ & $07: 52 \mathrm{a}$ & $\langle\mathrm{DIR}\rangle$ \\
$02 / 23 / 99$ & $07: 52 \mathrm{a}$ & $\langle\mathrm{DIR}\rangle$ &. \\
$01 / 11 / 99$ & $02: 53 \mathrm{p}$ & \multicolumn{2}{c}{787 baserun1.dat } \\
$09 / 28 / 98$ & $12: 42 \mathrm{a}$ & 498,181 DA3BE4.BAK \\
$01 / 11 / 99$ & $03: 05 \mathrm{p}$ & 88.269 DA3BE4.BPF \\
$01 / 11 / 99$ & $03: 05 \mathrm{p}$ & 11.999 DA3BE4.bsr \\
$01 / 11 / 99$ & $02: 52 \mathrm{p}$ & & 578,875 DA3BE4.BTF
\end{tabular}


Title: Total System Performance Assessment - License Application Design Selection (LADS) Phase 1 Analysis for Post-Closure Ventilation (Design Alternative 3)

Document Identifier: B00000000-01717-0210-00066 REV 00

\begin{tabular}{|c|c|c|}
\hline $01 / 11 / 9$ & $03: 05 p$ & 2,658.698 DA3BE4.btr \\
\hline $01 / 11 / 9$ & $03: 05 \mathrm{p}$ & 2,447 da3be4.out \\
\hline $01 / 11 / 9$ & $02: 52 p$ & 498,362 DA3BE4.RP \\
\hline $04 / 04 / 9$ & $11: 43 p$ & 11,979 da3 be4 tol \\
\hline $01 / 11 / 9$ & $02: 38 p$ & 6,936 da3be $4 . t 02$ \\
\hline $04 / 04 / 9$ & $11: 44 p$ & 11,964 da3be4.t03 \\
\hline $04 / 04 / 9$ & $11: 44 p$ & 12,266 da3 be $4 . t 04$ \\
\hline $01 / 11 / 9$ & $02: 38 \mathrm{p}$ & 6,224 da3be4.t05 \\
\hline $04 / 04 / 9$ & $11: 44 \mathrm{p}$ & 11,715 da3be4.t06 \\
\hline $03 / 28 / 9$ & $07: 25 a$ & 6,070 da3be4.t07 \\
\hline $03 / 27 / 9$ & $09: 33 a$ & 6.002 da3be $4 . t 08$ \\
\hline $03 / 28 / 9$ & $07: 30 \mathrm{a}$ & 6.002 da3be4.t09 \\
\hline $03 / 27 / 9$ & $09: 33 \mathrm{a}$ & 6,002 da3be4.t 10 \\
\hline $03 / 27 / 9$ & $09: 34 a$ & 6.070 da3be4.t1l \\
\hline $03 / 27 / 9$ & $09: 34 a$ & 6,070 da3be4.t 12 \\
\hline $03 / 27 / 9$ & $09: 35 \mathrm{a}$ & 6,070 da3be $4 . t 13$ \\
\hline $03 / 27 / 9$ & $09: 35 \mathrm{a}$ & 6,070 da3be $4 . t 14$ \\
\hline $03 / 27 / 9$ & $09: 35 \mathrm{a}$ & 6,070 da3be $4 . t 15$ \\
\hline $03 / 27 / 9$ & $08: 27 \mathrm{a}$ & 6,070 da3be $4 . t 16$ \\
\hline $03 / 27 / 9$ & $08: 27 \mathrm{a}$ & 6,002 da3be4.t17 \\
\hline $03 / 27 / 9$ & $08: 28 \mathrm{a}$ & 6,002 da3be $4 . t 18$ \\
\hline $03 / 27 / 9$ & $08: 34 a$ & 6,002 da3be4.t19 \\
\hline $01 / 06 / 9$ & $08: 47 p$ & 6.159 da3 be $4 . t 20$ \\
\hline $03 / 27 / 9$ & $08: 35 a$ & 6,002 da3be $4 . t 21$ \\
\hline $03 / 27 / 9$ & $08: 36 a$ & 6,070 da3be $4 . t 22$ \\
\hline $03 / 27 / 9$ & $08: 41 \mathrm{a}$ & 6.070 da3be $4 . t 23$ \\
\hline $03 / 27 / 9$ & $08: 41 \mathrm{a}$ & 6,070 da3be 4.124 \\
\hline $03 / 27 / 9$ & $09: 41 \mathrm{a}$ & 6.002 da3be $4 . t 25$ \\
\hline $03 / 27 / 9$ & $09: 41 \mathrm{a}$ & 6.070 da3be $4 . t 26$ \\
\hline $03 / 27 / 9$ & $09: 41 \mathrm{a}$ & 698 da3be $4 . t 27$ \\
\hline $03 / 27 / 9$ & $09: 41 \mathrm{a}$ & 6,002 da3be $4 . t 28$ \\
\hline $03 / 27 / 9$ & $09: 42 \mathrm{a}$ & 6,002 da3be $4 . t 29$ \\
\hline $03 / 27 / 9$ & $09: 42 \mathrm{a}$ & 6.070 da 3 be $4 . t 30$ \\
\hline $03 / 27 / 9$ & $09: 42 \mathrm{a}$ & 6,070 da3be $4 . t 31$ \\
\hline $03 / 27 / 9$ & $09: 43 a$ & 6,070 da 3 be $4 . t 32$ \\
\hline $03 / 27 / 9$ & $09: 43 a$ & 6,070 da3be $4 . t 33$ \\
\hline $03 / 30 / 9$ & $02: 38 p$ & 2.874 da3be $4 . t 34$ \\
\hline $01 / 06 / 9$ & $08: 47 p$ & $2.691 \mathrm{da} 3 \mathrm{be} 4.135$ \\
\hline $03 / 30 / 9$ & $02: 30 p$ & 1.990 da3be $4 . t 36$ \\
\hline $04 / 01 / 9$ & $06: 57 \mathrm{a}$ & 1.865 da3be $4 . \mathrm{t} 37$ \\
\hline $01 / 12 / 9$ & $09: 41 \mathrm{a}$ & 3.086 DOSE.DAT \\
\hline $10 / 27 / 9$ & $04: 00 \mathrm{a}$ & 5.527 EGAVGA.BGI \\
\hline $01 / 11 / 9$ & $02: 53 p$ & 160.935 ptrk.expval \\
\hline
\end{tabular}


Title: Total System Performance Assessment - License Application Design Selection (LADS) Phase 1 Analysis for Post-Closure Ventilation (Design Alternative 3)

Document Identifier: B00000000-01717-0210-00066 REV 00

Page I-6 of $1-7$

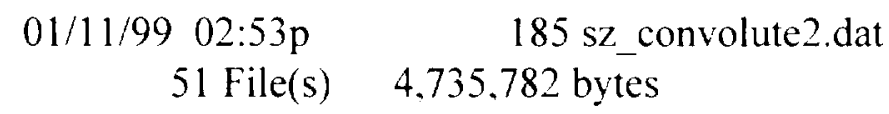

Directory of G:\d3be6

\begin{tabular}{|c|c|c|}
\hline 2/23/99 & $07: 52 \mathrm{a}$ & $<\mathrm{DIR}>$ \\
\hline $02 / 23 / 99$ & $07: 52 \mathrm{a}$ & $<\mathrm{DIR}>$ \\
\hline $01 / 11 / 99$ & $03: 40 p$ & 788 baserun 1.dat \\
\hline $01 / 11 / 99$ & $02: 52 \mathrm{p}$ & 498.362 DA3BE6.BAK \\
\hline $01 / 11 / 99$ & $07: 38 \mathrm{p}$ & 88.269 DA3BE6.BPF \\
\hline $01 / 11 / 99$ & $07: 38 \mathrm{p}$ & 11,999 DA3BE6.bsr \\
\hline $01 / 11 / 99$ & $03: 46 \mathrm{p}$ & 580,675 DA3BE6.BTF \\
\hline $01 / 11 / 99$ & $07: 38 \mathrm{p}$ & 25,695,098 DA3BE6.btr \\
\hline $01 / 11 / 99$ & $07: 38 \mathrm{p}$ & 2.447 da3be6.out \\
\hline $01 / 11 / 99$ & $03: 45 p$ & 498,362 DA3BE6.RP \\
\hline $04 / 04 / 98$ & $11: 43 p$ & 11.979 da3be $6 . t 01$ \\
\hline $01 / 11 / 99$ & $02: 38 \mathrm{p}$ & 6.936 da3be $6 . t 02$ \\
\hline $04 / 04 / 98$ & $11: 44 \mathrm{p}$ & 11.964 da3be 6.103 \\
\hline $04 / 04 / 98$ & $11: 44 p$ & 12.266 da3be $6 . t 04$ \\
\hline $01 / 11 / 99$ & $02: 38 \mathrm{p}$ & 6,224 da3be $6 . t 05$ \\
\hline $04 / 04 / 98$ & $11: 44 \mathrm{p}$ & 11.715 da3be $6 . t 06$ \\
\hline $03 / 28 / 98$ & $07: 25 \mathrm{a}$ & 6,070 da3be 6.107 \\
\hline $03 / 27 / 98$ & $09: 33 \mathrm{a}$ & 6,002 da3be 6.108 \\
\hline $03 / 28 / 98$ & $07: 30 \mathrm{a}$ & 6,002 da3be 6.109 \\
\hline $03 / 27 / 98$ & $09: 33 \mathrm{a}$ & 6,002 da3be 6.110 \\
\hline $03 / 27 / 98$ & $09: 34 a$ & 6.070 da3be6.t1 1 \\
\hline $03 / 27 / 98$ & $09: 34 \mathrm{a}$ & 6,070 da3be $6 . t 12$ \\
\hline $03 / 27 / 98$ & $09: 35 \mathrm{a}$ & 6,070 da3be $6 . t 13$ \\
\hline $03 / 27 / 98$ & $09: 35 \mathrm{a}$ & 6.070 da3be6.t14 \\
\hline $03 / 27 / 98$ & $09: 35 \mathrm{a}$ & 6,070 da3be 6.115 \\
\hline $03 / 27 / 98$ & $08: 27 \mathrm{a}$ & 6,070 da3be $6 . t 16$ \\
\hline $03 / 27 / 98$ & $08: 27 \mathrm{a}$ & 6,002 da3be $6 . \mathrm{t} 17$ \\
\hline $03 / 27 / 98$ & $08: 28 \mathrm{a}$ & 6,002 da3be6.t 18 \\
\hline $03 / 27 / 98$ & $08: 34 a$ & 6,002 da3be $6 . t 19$ \\
\hline $01 / 06 / 99$ & $08: 47 \mathrm{p}$ & 6.159 da3be $6 . t 20$ \\
\hline $03 / 27 / 98$ & $08: 35 \mathrm{a}$ & 6,002 da3 be 6.121 \\
\hline $03 / 27 / 98$ & $08: 36 \mathrm{a}$ & 6.070 da3 be 6.122 \\
\hline 03/27/98 & $08: 41 \mathrm{a}$ & 6.070 da3 be $6 . t 23$ \\
\hline 03/27/98 & $08: 41 \mathrm{a}$ & 6.070 da3 be $6 . t 24$ \\
\hline 03/27/98 & $09: 41 \mathrm{a}$ & 6.002 da3 be $6 . t 25$ \\
\hline $03 / 27 / 98$ & $09: 41 \mathrm{a}$ & 6.070 da3be $6 . t 26$ \\
\hline $03 / 27 / 98$ & $09: 41 \mathrm{a}$ & 698 da3be $6 . t 27$ \\
\hline $03 / 27 / 98$ & $09: 41 \mathrm{a}$ & 6.002 da3be $6 . t 28$ \\
\hline
\end{tabular}


Title: Total System Performance Assessment - License Application Design Selection (LADS) Phase 1 Analysis for Post-Closure Ventilation (Design Alternative 3)

Document Identifier: B00000000-01717-0210-00066 REV 00

Page 1-7 of I-7

$\begin{array}{ccc}03 / 27 / 98 & 09: 42 a & 6,002 \text { da3be6.t29 } \\ 03 / 27 / 98 & 09: 42 a & 6,070 \text { da3be6.t30 } \\ 03 / 27 / 98 & 09: 42 a & 6,070 \text { da3be6.t31 } \\ 03 / 27 / 98 & 09: 43 a & 6,070 \text { da3be6.t32 } \\ 03 / 27 / 98 & 09: 43 a & 6,070 \text { da3be6.t33 } \\ 03 / 30 / 98 & 02: 38 \mathrm{p} & 2,874 \text { da3be6.t34 } \\ 01 / 06 / 99 & 08: 47 \mathrm{p} & 2,691 \text { da3be6.t35 } \\ 03 / 30 / 98 & 02: 30 \mathrm{p} & 1,990 \text { da3be6.t36 } \\ 04 / 01 / 98 & 06: 57 \mathrm{a} & 1.865 \text { da3be6.t37 } \\ 01 / 12 / 99 & 09: 42 \mathrm{a} & 28,286 \text { DOSE.DAT } \\ 10 / 27 / 92 & 04: 00 \mathrm{a} & 5.527 \text { EGAVGA.BGI } \\ 01 / 11 / 99 & 03: 41 \mathrm{p} & 160,936 \text { ptrk.expval } \\ 01 / 11 / 99 & 03: 44 \mathrm{p} & 186 \text { sz_convolute2.dat } \\ 51 \text { File(s) } & 27,799,366 \text { bytes }\end{array}$




\section{Performance Assessment Operations}

Calculation

Title: Total System Performance Assessment - License Application Design Selection (LADS) Phase 1 Analysis for Post-Closure Ventilation (Design Alternative 3)

Document Identifier: B00000000-01717-0210-00066 REV 00

Page II-1 of II-4

\section{Attachment II}

\section{Result Figures}


Title: Total System Performance Assessment - License Application Design Selection (LADS) Phase 1 Analysis for Post-Closure Ventilation (Design Alternative 3)

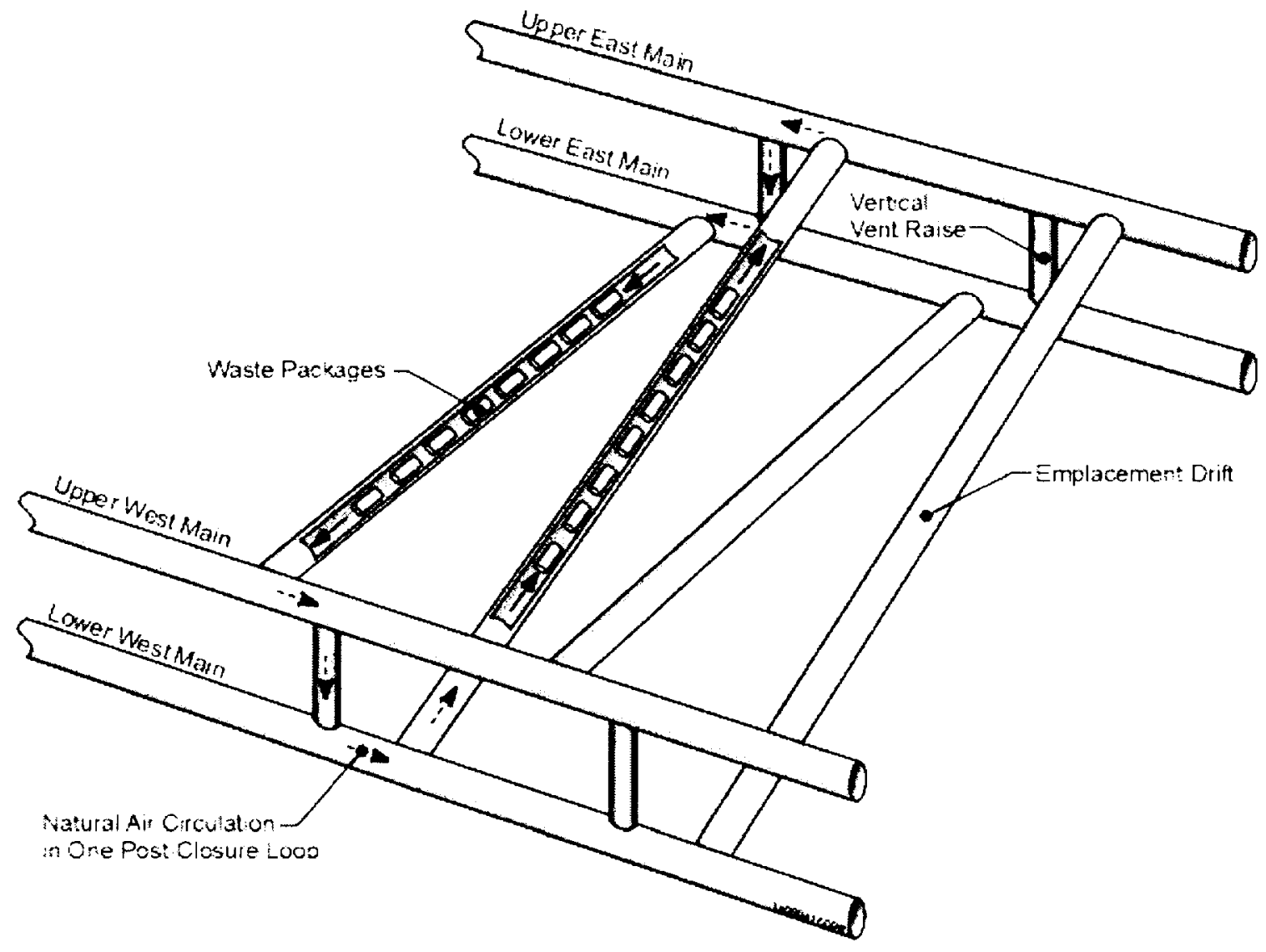

Danko (Bow Tie) Concept

Figure 1 Schematic Of Bow Tie Configuration For Post-Closure Ventilation. 
Title: Total System Performance Assessment - License Application Design Selection (LADS) Phase 1 Analysis for Post-Closure Ventilation (Design Alternative 3)

\section{Design Alternative 3 10,000-yr Total Dose-Rate History All Pathways, 20 km}

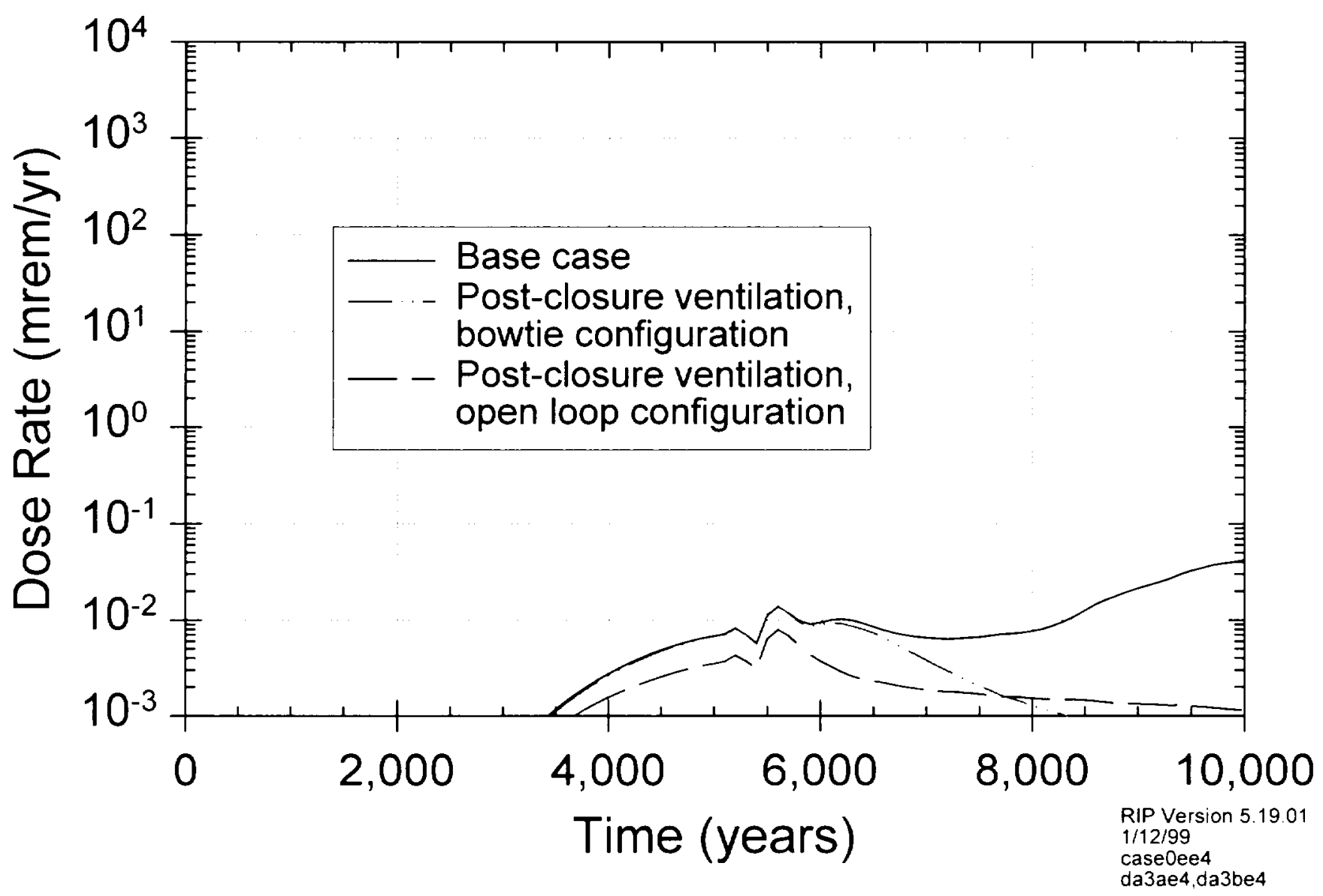

Figure 2. Base Case And Post-Closure Ventilation (D3) 10,000-year Dose Rate Results. 
Title: Total System Performance Assessment - License Application Design Selection (LADS) Phase 1 Analysis for Post-Closure Ventilation (Design Alternative 3)

\section{Design Alternative 3 1,000,000-yr Total Dose-Rate History} All Pathways, 20 km

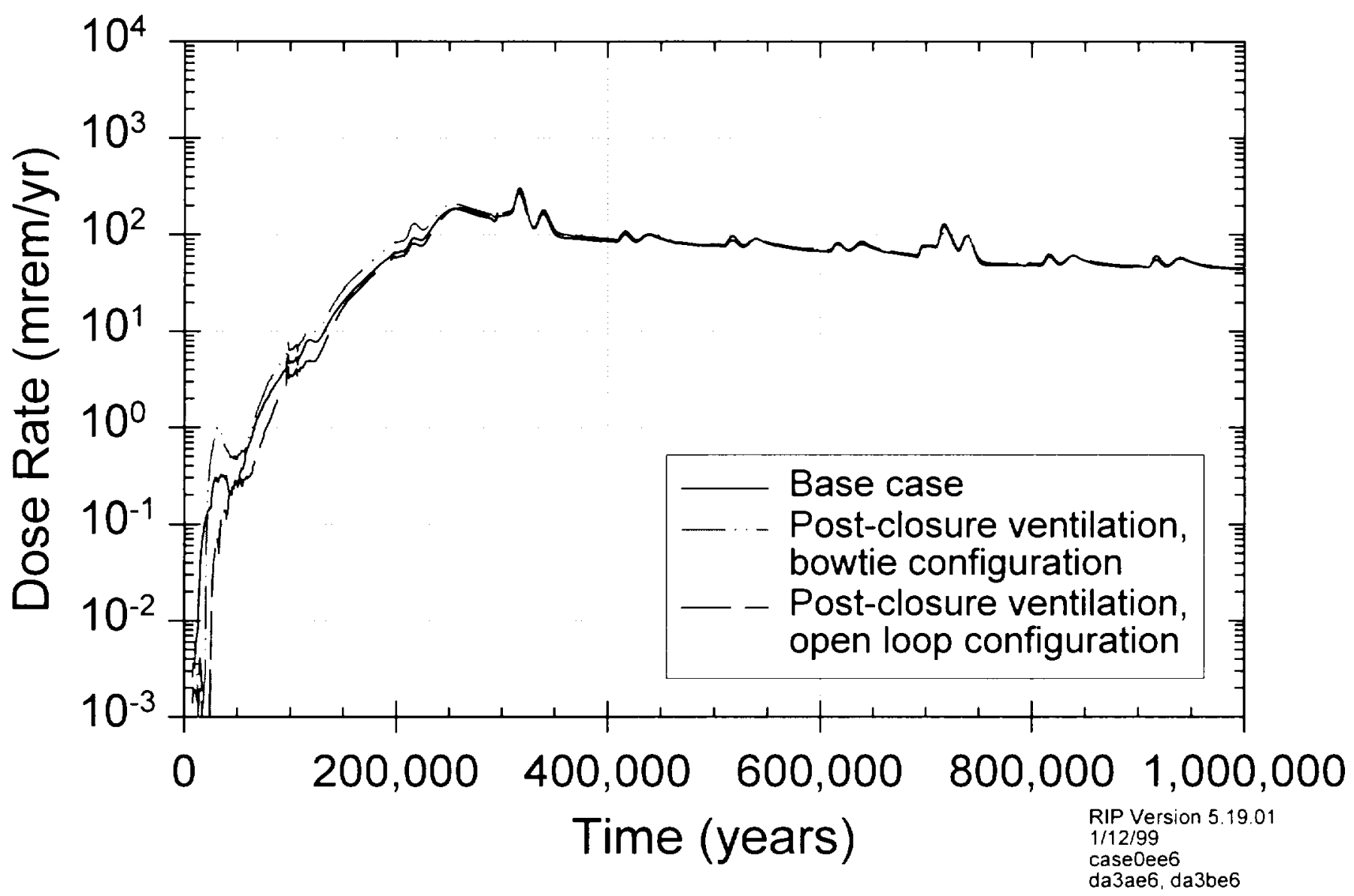

Figure 3. Base Case And Post-Closure Ventilation (D3) 1,000,000-year Dose Rate Results. 